\title{
BRAF-activated IncRNA predicts gastrointestinal cancer patient prognosis: a meta-analysis
}

\author{
Yang-Hua Fan ${ }^{1, *}$, Min-Hua Ye ${ }^{1, *}$, Lei Wu ${ }^{1}$, Miao-Jing Wu ${ }^{1}$, Shi-Gang Lu ${ }^{1}$, Xin-Gen Zhu ${ }^{1}$ \\ ${ }^{1}$ Department of Neurosurgery, The Second Affiliated Hospital of Nanchang University, Nanchang 330006, Jiangxi Province, \\ People's Republic of China \\ *These authors contributed equally to this work
}

Correspondence to: Xin-Gen Zhu, email: zxg2008vip@163.com

Shi-Gang Lu, email: Ivshigang1982@sina.com

Keywords: BANCR, long non-coding RNA, gastrointestinal cancer, biomarker, meta-analysis

Received: October 20, $2016 \quad$ Accepted: December 13, $2016 \quad$ Published: December 21, 2016

\begin{abstract}
BRAF activated non-coding RNA (BANCR) is often dysregulated in cancer. We performed a meta-analysis to clarify its functions as a prognostic indicator in malignant tumors. We searched the PubMed, Medline, OVID, Cochrane Library, and Web of Science databases to identify BANCR-related studies. Nine original studies and 898 total patients were included in the meta-analysis. Hazard ratios (HR) and $95 \%$ confidence intervals (CI) were extracted from the included studies to determine the relationship between BANCR expression and patient overall survival (OS). Odds ratios (OR) were calculated using RevMan 5.3 software to assess associations between BANCR expression and pathological parameters. High BANCR expression correlated with lymph node metastasis (LNM) (OR $=3.41,95 \% \mathrm{CI}: 1.82-6.37, P=0.0001)$, distant metastasis $(D M)(O R=2.98,95 \% C I: 1.76-5.07, P<0.0001)$, tumor stage (OR = 3.11, 95\% CI: 1.89-5.12, $Z=3.25, P<0.0001$ ), and poor OS (pooled HR $=1.98$, 95\% CI: 1.20-3.27, $P=0.008$ ) in gastrointestinal (GI) cancer patients, but not in non-GI cancer patients. Our results support the notion that BANCR as a promising prognostic biomarker in Chinese patients with GI cancer.
\end{abstract}

\section{INTRODUCTION}

Long noncoding RNAs (lncRNAs) are transcribed RNA molecules $>200$ nucleotides (nt) in length that lack an open reading frame [1]. IncRNAs have important functions in disease, including epigenetic, transcriptional, and posttranscriptional regulation [2]. Recent studies have reported lncRNA dysregulation in various cancer types [3-6]. Some lncRNAs play roles in cancer progression, promoting or inhibiting proliferation, invasion and metastasis [7-8], and many are promising prognostic markers [9]. Approximately 8.2 million people die from malignant tumors and 14.1 million people are diagnosed with cancer worldwide each year [10]. According to the American National Center for Health Statistics, approximately 600 thousand Americans will die of cancer in 2016 [11]. Novel biomarkers, such as lncRNAs, that enhance prognostic accuracy and aid in therapeutic decisionmaking are essential for improving cancer patient outcomes.

BRAF-activated IncRNA (BANCR), a 693nt IncRNA encoded on human chromosome 9, was discovered by McCarthy [12] and Flockhart [13] and colleagues in 2012. BANCR is highly expressed in melanoma and promotes melanoma cell migration [12-13]. Evidence suggests that BANCR might play important roles in cancer growth and metastasis [14] and may be a prognostic indicator in certain cancers. However, most studies reported so far have been limited by discrete outcome and sample size. We performed an updated metaanalysis to determine the prognostic value of BANCR in cancer patients.

\section{RESULTS}

\section{Literature search analysis}

The detailed BANCR study screening process is shown in Figure 1. Based on inclusion and exclusion criteria, nine studies and 898 patients were included in the meta-analysis (Table 1) [15-23]. An average number of 99.8 subjects were analyzed in each study (range, 54 to 184). All studies were conducted in China and were 
Table 1: Basic characteristics of all studies included in the meta-analysis

\begin{tabular}{|c|c|c|c|c|c|c|c|c|c|c|c|c|c|c|}
\hline \multirow{3}{*}{ Study } & \multirow{3}{*}{ Year } & \multirow{3}{*}{ Region } & \multirow{3}{*}{$\begin{array}{c}\text { Tumor } \\
\text { type }\end{array}$} & \multirow{3}{*}{$\begin{array}{c}\text { Sample } \\
\text { size }\end{array}$} & \multicolumn{6}{|c|}{ BANCR expression } & \multirow{3}{*}{ Outcome } & \multirow{3}{*}{$\begin{array}{l}\text { Survival } \\
\text { Analysis }\end{array}$} & \multirow{3}{*}{ HR(95\% CI) } & \multirow{3}{*}{ Method } \\
\hline & & & & & \multicolumn{3}{|c|}{ High } & \multicolumn{3}{|c|}{ Low } & & & & \\
\hline & & & & & Total & LNM & DM & Total & LNM & DM & & & & \\
\hline $\mathrm{Guo}^{[15]}$ & 2014 & China & $\mathrm{CRC}$ & 60 & 18 & 14 & - & 42 & 16 & - & - & - & - & qRT-PCR \\
\hline $\mathrm{He}^{[16]}$ & 2016 & China & $\mathrm{BC}$ & 54 & 19 & 1 & - & 35 & 9 & - & - & - & - & qRT-PCR \\
\hline $\mathrm{Li}^{[17]}$ & 2015 & China & GC & 184 & 92 & 60 & 12 & 92 & 43 & 0 & OS & Multivariate & $1.511(1.025-2.227)$ & qRT-PCR \\
\hline $\operatorname{Liao}^{[18]}$ & 2016 & China & PTC & 92 & 29 & 14 & - & 63 & 30 & - & - & - & - & qRT-PCR \\
\hline $\operatorname{Liu}^{[19]}$ & 2016 & China & ESCC & 142 & 71 & 57 & 30 & 71 & 33 & 19 & OS & Multivariate & $2.238(1.052-4.762)$ & qRT-PCR \\
\hline Peng ${ }^{[20]}$ & 2016 & China & OsC & 84 & 42 & - & 20 & 42 & - & 10 & OS & Multivariate & $2.934(1.123-7.664)$ & qRT-PCR \\
\hline $\mathrm{Su}^{[21]}$ & 2015 & China & $\mathrm{RB}$ & 60 & 30 & - & - & 30 & - & - & os & Multivariate & $2.903(1.049-8.036)$ & qRT-PCR \\
\hline $\operatorname{Sun}^{[22]}$ & 2014 & China & NSCLC & 113 & 53 & 19 & - & 60 & 40 & - & OS & Multivariate & $0.496(0.262-0.938)$ & qRT-PCR \\
\hline Zhou $^{[23]}$ & 2016 & China & $\mathrm{HCC}$ & 109 & 54 & - & - & 55 & - & - & Os & Multivariate & $4.245(1.324-13.609)$ & qRT-PCR \\
\hline
\end{tabular}

Note: The dashes represent no data.

Abbreviations: CRC, colorectal cancer; BC ,bladder cancer; GC, gastric cancer; PTC ,papillary thyroid cancer; ESCC, Esophageal Squamous Cell Carcinoma; OSC, osteosarcoma; RB ,retinoblastoma; NSCLC, non-small cell lung cancer; HCC, hepatocellular carcinoma; OS, overall survival; LNM, lymph node metastasis; DM, distant metastasis.

published between 2014 and 2016. The included studies focused on colorectal cancer (CRC) [15], bladder cancer (BC) [16], gastric cancer (GC) [17], papillary thyroid cancer (PTC) [18], esophageal squamous cell carcinoma (ESCC) [19], osteosarcoma (OSC) [20], retinoblastoma (RB) [21], non-small cell lung cancer (NSCLC) [22], or hepatocellular carcinoma (HCC) [23]. BANCR expression was measured in tumor specimens. Lymph node metastasis (LNM), distant metastasis (DM), and tumor stage assessments depended on individual pathology. The Newcastle-Ottawa Scale (NOS) confirmed that all studies were of good quality (Table 2).

\section{Association between BANCR expression and OS}

We performed a cumulative meta-analysis to assess the role of BANCR in cancer patient overall survival (OS). Six of the nine included studies with 645 total patients reported the relationship between OS and BANCR. The random effects model was used due to significant heterogeneity $\left(\mathrm{I}^{2}=74 \%, P=0.002\right)$. The HR for the high BANCR expression group versus the low expression group was 1.81 (95\% CI: 0.99-3.29, $P=0.05$; Figure 2). Due to the presence of heterogeneity, subgroups were analyzed based on cancer type (gastrointestinal [GI] or non-GI cancer). This revealed an association between BANCR and OS in GI cancer patients $(\mathrm{HR}=1.98,95 \% \mathrm{CI}: 1.20-3.27, P=0.008)$, but not between BANCR and non-GI cancer patients $(\mathrm{HR}=1.54,95 \% \mathrm{CI}: 0.42-5.63, P=0.51)$. There was no significant heterogeneity among GI cancer studies $\left(\mathrm{I}^{2}=37 \%, P=0.20\right)$. In a sensitivity analysis of all six studies, heterogeneity disappeared after the Sun, et al. study [22] was excluded $\left(\mathrm{I}^{2}=16 \%, P=0.31\right)$. BANCR and $\mathrm{OS}$ were associated $(\mathrm{HR}=1.94,95 \% \mathrm{CI}: 1.44-5.62$,
$P<0.0001)$ in the five remaining studies. These results demonstrated that high BANCR expression might correlate with shorter OS in GI cancer patients in China, and BANCR was an independent factor for OS in these patients.

\section{Association between BANCR expression and LNM}

Data from 645 cancer patients in six eligible studies were collected and analyzed. The random effects model was used due to significant heterogeneity $\left(\mathrm{I}^{2}=87 \%\right.$, $P<0.00001)$. Meta-regression analysis and subgroup analysis (GI or non-GI cancer) were performed to explore heterogeneity sources. In the subgroup analysis, BANCR and LNM were associated in GI cancers $(\mathrm{OR}=3.41,95 \%$ CI: $1.82-6.37, P=0.0001)$, but not in non-GI cancers $(\mathrm{HR}=0.43,95 \% \mathrm{CI}: 0.15-1.26, P=0.06$; Figure 3$)$. There was no significant heterogeneity among GI cancer studies $\left(\mathrm{I}^{2}=44 \%, P<0.17\right)$. These results demonstrated that high BANCR expression predicted a higher likelihood of LNM in GI cancer patients.

\section{Association between BANCR expression and DM}

Analysis of 410 patients from three eligible studies demonstrated association between BANCR levels and cancer patients with DM (Figure 4). Analysis by the fixed effects model showed no significant heterogeneity $\left(\mathrm{I}^{2}=45 \%, P=0.16\right)$ and the pooled OR was $2.98(95 \%$ CI: 1.76-5.07, $P<0.0001$; high versus low BANCR; Figure 4). As a result, patients with DM clustered in the high BANCR expression group. These results indicated that high BANCR expression predicted increased probability of DM. 
Table 2: Study quality was assessed according to the newcastle-ottawa scale

\begin{tabular}{|c|c|c|c|c|c|c|c|c|c|}
\hline & ry & $\begin{array}{c}\text { Adequate of } \\
\text { case definition }\end{array}$ & $\begin{array}{c}\text { Representativeness of } \\
\text { the cases }\end{array}$ & $\begin{array}{l}\text { Selection of } \\
\text { Controls }\end{array}$ & $\begin{array}{l}\text { Definition of } \\
\text { Controls }\end{array}$ & $\begin{array}{l}\text { Comparability of } \\
\text { cases and controls }\end{array}$ & $\begin{array}{l}\text { Ascertainment } \\
\text { of exposure }\end{array}$ & $\begin{array}{c}\text { Same } \\
\text { method of } \\
\text { ascertainment }\end{array}$ & $\begin{array}{l}\text { Non-Response } \\
\text { rate }\end{array}$ \\
\hline
\end{tabular}

\begin{tabular}{|c|c|c|c|c|c|c|c|c|c|}
\hline Guo & China & $\star$ & $\star$ & $\star$ & NA & $\star \star$ & $\star$ & $\star$ & NA \\
\hline $\mathrm{He}$ & China & $\star$ & $\star$ & $\star$ & NA & $\star \star$ & $\star$ & $\star$ & NA \\
\hline $\mathrm{Li}$ & China & $\star$ & $\star$ & $\star$ & $\star$ & $\star \star$ & $\star$ & $\star$ & NA \\
\hline Liao & China & $\star$ & $\star$ & $\star$ & NA & $\star \star$ & $\star$ & $\star$ & NA \\
\hline Liu & China & $\star$ & $\star$ & $\star$ & $\star$ & $\star \star$ & $\star$ & $\star$ & NA \\
\hline Peng & China & $\star$ & $\star$ & $\star$ & $\star$ & $\star \star$ & $\star$ & $\star$ & NA \\
\hline $\mathrm{Su}$ & China & $\star$ & $\star$ & $\star$ & NA & $\star \star$ & $\star$ & $\star$ & NA \\
\hline Sun & China & $\star$ & $\star$ & $\star$ & $\star$ & $\star \star$ & $\star$ & $\star$ & NA \\
\hline Zhou & China & $\star$ & $\star$ & $\star$ & NA & $\star \star$ & $\star$ & $\star$ & NA \\
\hline
\end{tabular}

Notes: The quality of the article is through the number of stars $\left(^{*}\right)$. Through the selection and exposure categories, each numbered item gets a star at most. A maximum of two stars can be given for comparability. NA: not available.

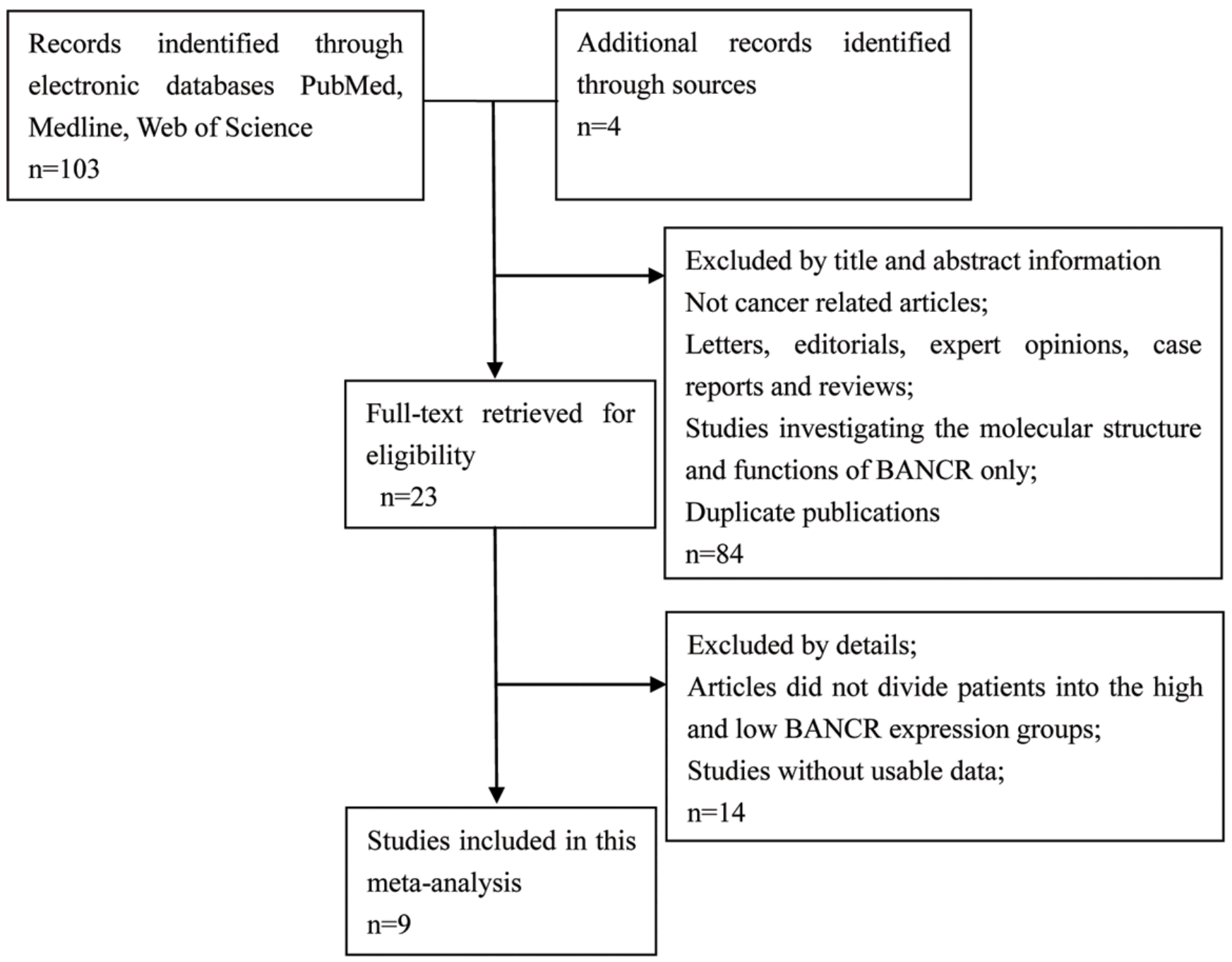

Figure 1: Flowchart depicting the literature search process, and study selection criteria. 


\section{Association between BANCR expression and tumor stage}

The relationship between BANCR expression and tumor stage was analyzed in 692 patients from eight eligible studies. Due to significant heterogeneity among the studies $\left(\mathrm{I}^{2}=88 \%, P<0.00001\right)$, the random effects model was used to calculate the pooled HR with corresponding 95\% CI. The OR of the high BANCR expression group versus the low expression group was 1.34 (95\% CI: 0.52-3.41, $P=0.55$; Figure 5). Subsequent subgroup analyses were performed based on cancer type. Higher BANCR expression corresponded with higher tumor grade, with a pooled OR of $3.11(95 \%$ CI: $1.89-5.12, P<0.00001$; Figure 5), with no obvious heterogeneity $\left(\mathrm{I}^{2}=34 \%, P=0.21\right)$ in GI cancer studies.

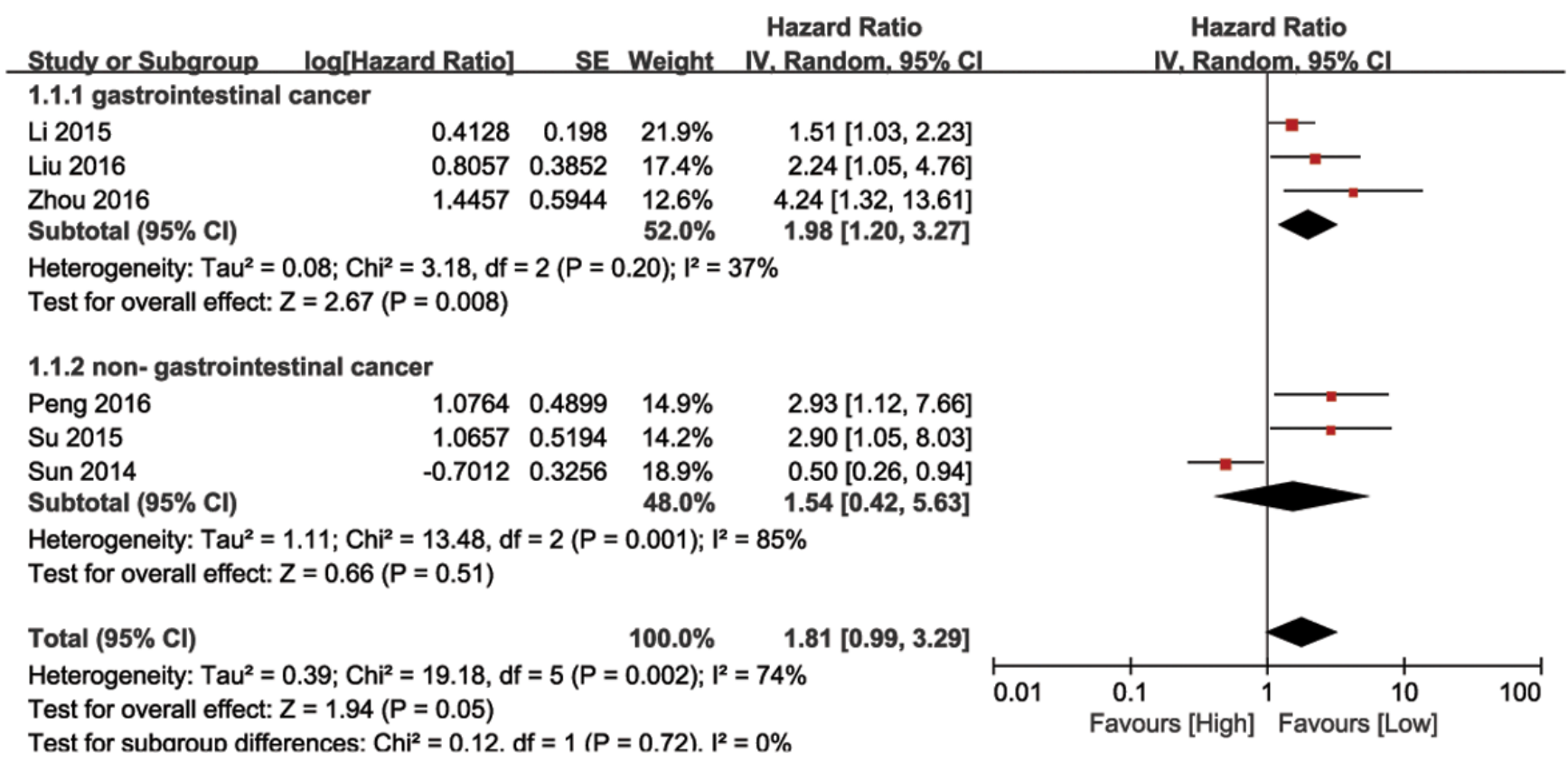

Figure 2: Forest plot showing the association between OS and BANCR expression in different cancer types.

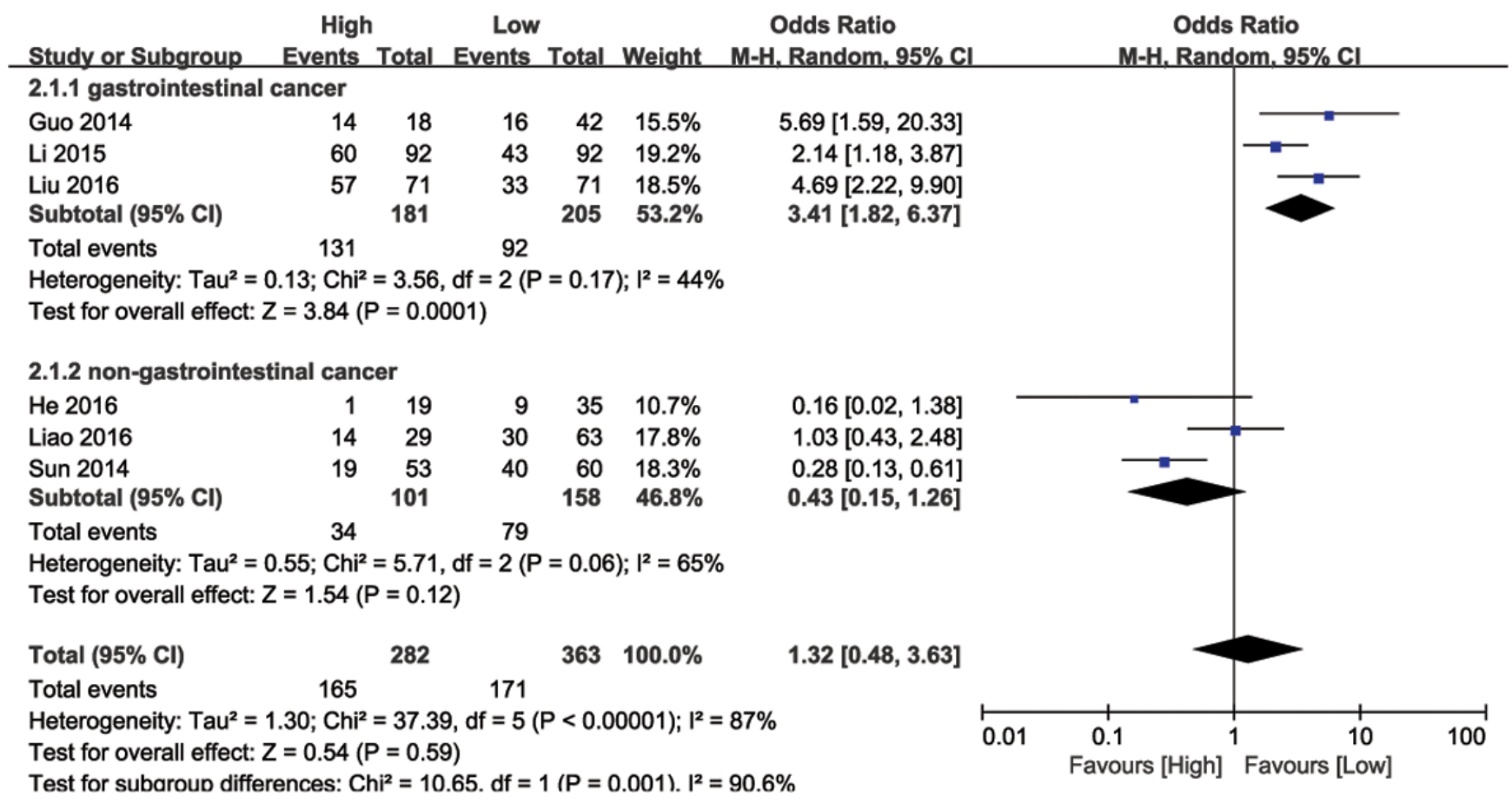

Figure 3: Forest plot showing the association between LNM and BANCR expression in different cancer types. 
However, significant heterogeneity existed across nonGI cancer studies $\left(\mathrm{I}^{2}=89 \%, P<0.00001\right)$, and BANCR was not associated with tumor stage in these cancers $(\mathrm{HR}=0.45,95 \%$ CI: 0.09-2.24, $P=0.06$; Figure 5) Our results demonstrated that higher BANCR expression predicted higher tumor stage in GI cancer patients in China.

\section{Publication bias}

For our meta-analysis of the association between BANCR expression and OS, Begg's funnel plot and Egger's test results $(P>|\mathrm{t}|=0.366,95 \% \mathrm{CI}$ : -3.643-7.867) showed no significant publication bias across the included studies (Figure 6).

\section{DISCUSSION}

The occurrence of metastasis in cancers indicates poor patient prognosis and hence is an important survival indicator [24-25]. In addition, LNM and DM are important for cancer patient TNM (tumor-nodemetastasis) staging, and for predicting patient prognosis. Since the precise metastasis mechanisms remain unknown in most cancers, molecular biomarkers play critical roles in cancer diagnosis, prognosis and treatment [26-27]. Finding new molecular markers that accurately predict tumor metastasis risk are of paramount importance for improving patient outcomes.

Mammalian genome analyses suggest that more than $80 \%$ of transcription is associated with lncRNAs [28].

\begin{tabular}{|c|c|c|c|c|c|c|c|c|c|c|}
\hline Study or Subgroup & $\begin{array}{c}\text { High } \\
\text { Events }\end{array}$ & Total & $\begin{array}{l}\text { Low } \\
\text { Events }\end{array}$ & Total & Weight & $\begin{array}{l}\text { Odds Ratio } \\
\text { M-H. Fixed. } 95 \% \mathrm{Cl}\end{array}$ & & $\begin{array}{r}\text { Odds } \\
\text { M-H. Fixe }\end{array}$ & $\begin{array}{l}\text { Ratio } \\
\text { ed. } 95 \% \mathrm{Cl}\end{array}$ & \\
\hline Li 2015 & 12 & 92 & 0 & 92 & $2.6 \%$ & $28.73[1.67,492.88]$ & & & & \\
\hline Liu 2016 & 30 & 71 & 19 & 71 & $65.9 \%$ & $2.00[0.99,4.06]$ & & & & \\
\hline Peng 2016 & 20 & 42 & 10 & 42 & $31.5 \%$ & $2.91[1.14,7.40]$ & & & & \\
\hline Total $(95 \% \mathrm{Cl})$ & & 205 & & 205 & $100.0 \%$ & $2.98[1.76,5.07]$ & & & & \\
\hline Total events & 62 & & 29 & & & & & & & \\
\hline $\begin{array}{l}\text { Heterogeneity: } \mathrm{Chi}^{2}= \\
\text { Test for overall effect: }\end{array}$ & $\begin{array}{l}3.67, d f=2 \\
Z=4.04(P\end{array}$ & $\begin{array}{l}(P=0 \\
<0.0 C\end{array}$ & $\begin{array}{l}.16) ;\left.\right|^{2}=4 \\
001)\end{array}$ & $45 \%$ & & & 0.01 & $\begin{array}{l}0.1 \\
\text { Favours [High] }\end{array}$ & $\begin{array}{lc}1 & 10 \\
& \text { Favours [Low] }\end{array}$ & 100 \\
\hline
\end{tabular}

Figure 4: Forest plot showing the association between DM and BANCR expression in different cancer types.

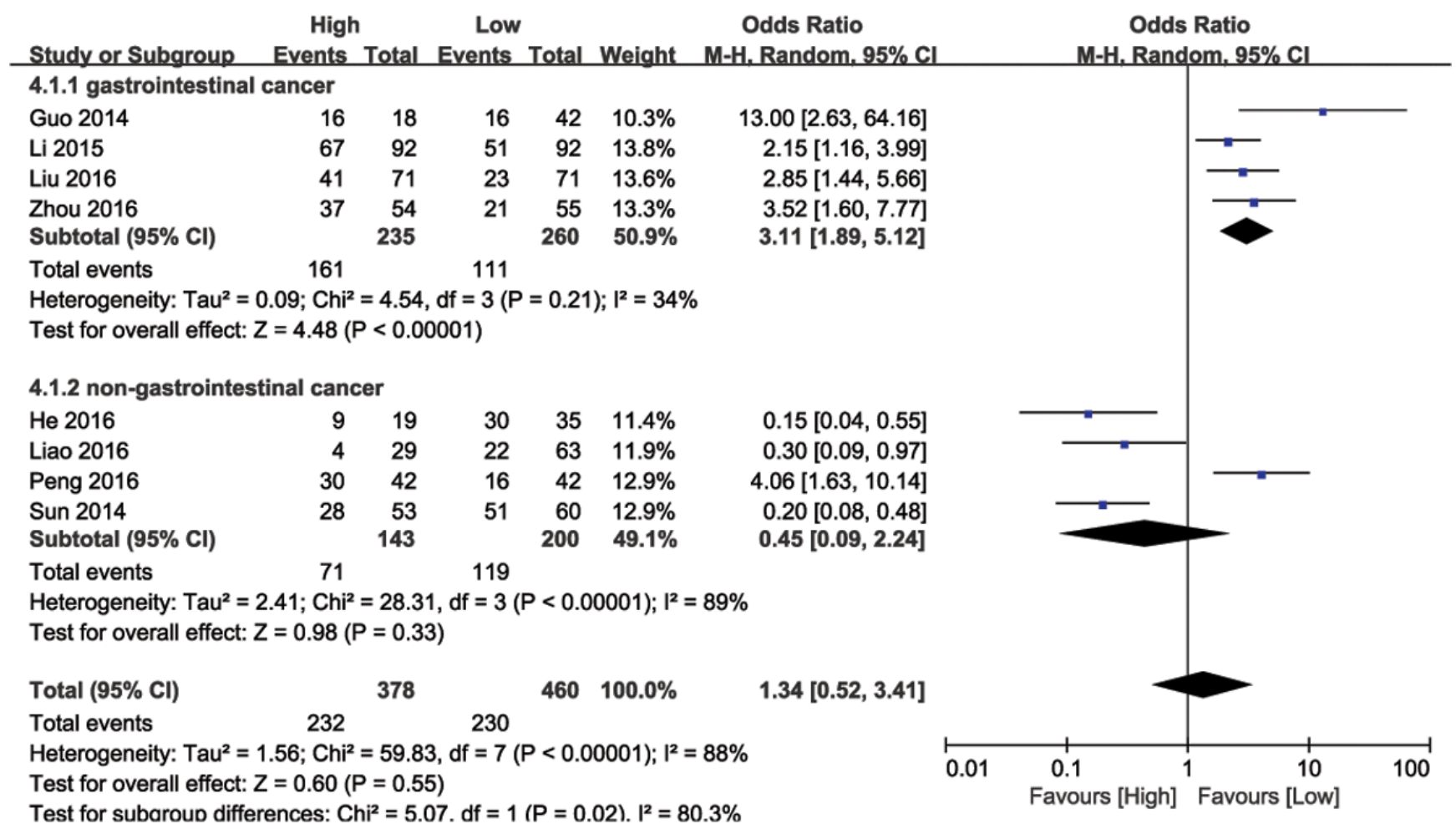

Figure 5: Forest plot showing meta-analysis of BANCR with respect to tumor stage in different cancer types. 
lncRNAs play central roles in the regulation of cell differentiation, development, and proliferation [29]. Due to specific lncRNA associations with tumor development, and their presence in body fluids and tumor tissues, lncRNAs are promising biomarkers for tumor diagnosis and monitoring [30].

BRAF-activated lncRNA (BANCR) was discovered in melanoma, and promotes melanoma cell migration [12]. BANCR appears to be associated with tumorigenesis, and is dysregulated in colorectal, bladder, gastric, papillary thyroid, and lung cancer, and in ESCC, osteosarcoma, and hepatocellular carcinoma [15-23]. However, assessments of the prognostic value of BANCR in cancer patients were contradictory and inconclusive. On one hand, BANCR knockdown inhibited the malignant progression of melanoma, colorectal cancer and osteosarcoma [12, 15, 20, 31]. These studies suggest that BANCR acts as an oncogene to promote tumor growth. However, BANCR may function as a tumor suppressor in lung cancer [22, 32], and conclusions from two papillary thyroid cancer studies were contradictory $[15,33]$. Because the role of BANCR as a molecular biomarker in human cancer was unclear, our study explored the prognostic value of BANCR in cancer patients via a meta-analysis.

Subgroup analyses in a fixed or random model allowed us to assess the role of BANCR in different cancer types. Our data showed that higher BANCR expression was indicative of advanced disease and poor prognosis in patients with GI cancer. By combining HRs from Cox multivariate analyses, we observed reduced
GI cancer patient OS in high BANCR expression groups as compared to low expression groups (pooled HR = 1.98, 95\% CI: $1.20-3.27, P=0.008)$. Higher BANCR expression was also associated with LNM (OR $=3.41$, 95\%CI: $1.82-6.37, P=0.0001), \mathrm{DM}(\mathrm{OR}=2.98,95 \%$ CI: $1.76-5.07, P<0.0001)$, and tumor stage (OR $=3.11$, 95\% CI:1.89-5.12, $P<0.00001)$ in these patients. These associations were not observed in non-GI cancer patients.

Certain limitations must be taken into account when interpreting the conclusions of our meta-analysis. First, all studies were from China. Therefore our data may not represent global populations. Second, the included cancer types and patient numbers were small. Third, the criterion for high BANCR expression varied for different studies. Additional studies are needed to confirm the function of BANCR in various cancers.

In conclusion, high BANCR expression was associated with LNM, DM, advanced tumor stage, and poor OS in multiple GI cancers. Our results support BANCR as a promising prognostic biomarker for GI cancer patients in China.

\section{MATERIALS AND METHODS}

\section{Literature search to identify relevant studies for meta-analysis}

According to standard meta-analysis guidelines [34-35], two authors (Yang-Hua Fan and Min-Hua Ye) independently performed systematic searches for relevant

\section{Begg's funnel plot with pseudo $95 \%$ confidence limits}

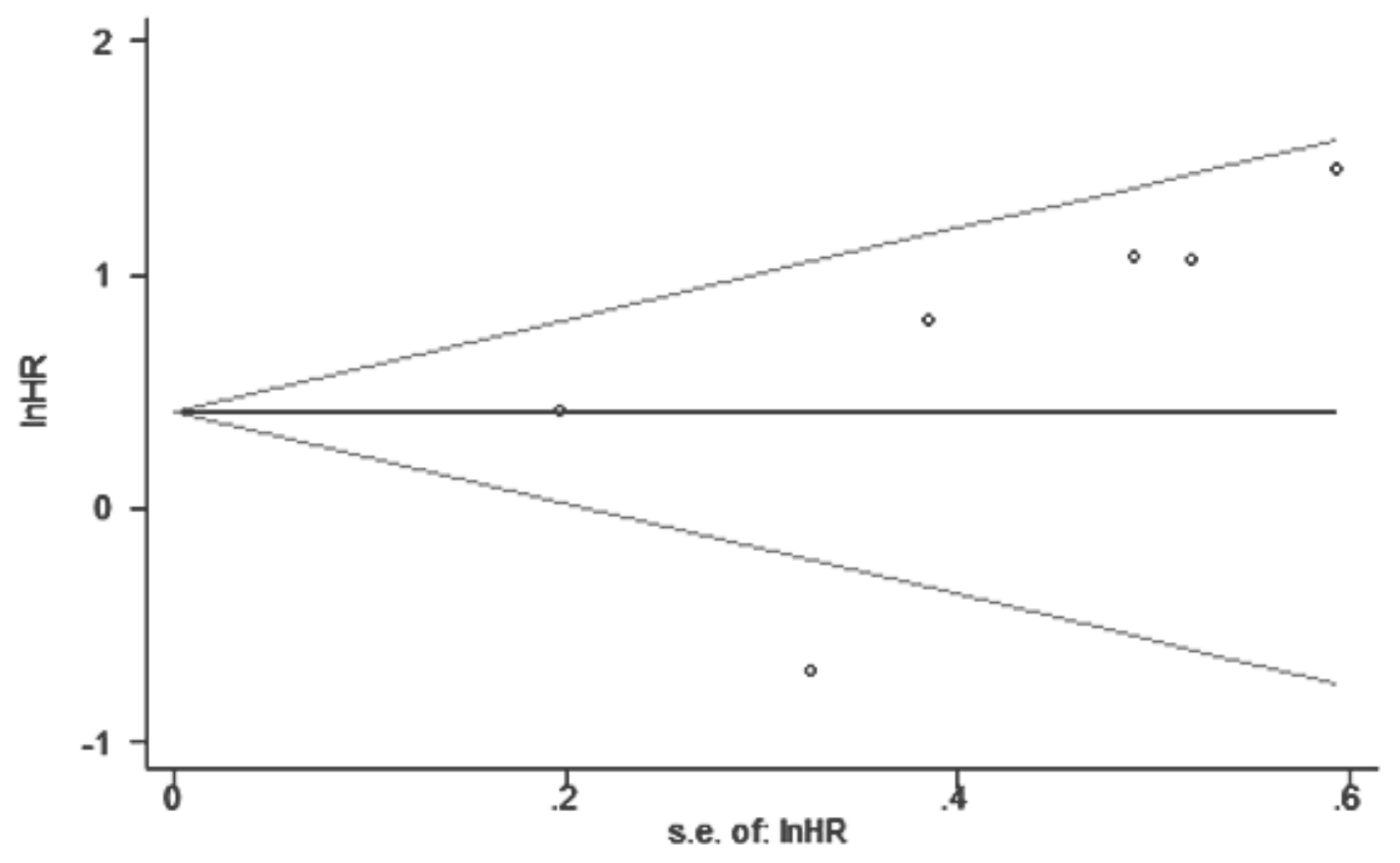

Figure 6: Funnel plot to assess publication bias with respect to the association of BANCR with OS in different cancer types. 
articles concerning BANCR as a prognostic biomarker for cancer patient survival via the online databases, OVID, PubMed, Medline, and Web of Science. The latest search was updated on October 10, 2016. We searched using both text and MeSH terminology approaches, with the terms 'BANCR', 'BRAF activated non-coding RNA', 'long intergenic noncoding RNA', 'IncRNA', 'noncoding RNA', 'cancer', tumor', carcinoma', neoplasm', 'prognostic', 'prognosis', 'outcome', 'survival' or 'recurrence'. The strategy was adjusted for each database to maximize chances of finding the appropriate articles. Manual searches were also performed using the reference lists of relevant articles.

\section{Selection criteria for study inclusion}

Two researchers, Yanghua Fan and Shi-Gang Lu, evaluated all included studies and extracted the data independently. Criteria used to include studies in the meta-analysis were as follows: 1) BANCR expression was measured in human tumor tissue, and patients were grouped according to BANCR level; 2) all tumors were confirmed by pathological or histological examinations; 3) studies statistically analyzed patient overall survival or pathological parameters such as LNM, DNM, and tumor stage, with respect to BANCR expression.

Exclusion criteria included: 1) articles that were reviews, letters, editorials, case reports and expert opinions; 2) non-English language and non-human studies; 3) studies lacking data listed in the inclusion criteria; 4) basic BANCR characterization studies.

\section{Data extraction from relevant studies}

Two reviewers, Yanghua Fan and Lei Wu, independently extracted and examined data from the selected original articles. Any literature assessment disagreements were resolved through a third reviewer, Xingen Zhu. The following details were collected from each study: first author surname, publication year, country, tumor type, sample size, number of patients with lymph node and distant metastasis, BANCR HR and 95\% CI for OS, and BANCR detection method.

\section{Statistical analysis}

Study quality was assessed according to the Newcastle-Ottawa Scale (NOS). Statistical analyses were performed using RevMan version 5.3 software. Heterogeneity among different studies was measured by the $Q$ and $I^{2}$ tests. A probability value of $\mathrm{I}^{2} \geq 50 \%$, and $P<0.1$ indicated significant heterogeneity [36]. A random effects or fixed effects model was used depending on heterogeneity analysis results. If there was significant heterogeneity among the studies, the random-effects model was adopted. Potential publication bias was assessed by the Begg's funnel plot through Stata 12.0 software. Pooled HRs and ORs were extracted from the published data. When HRs and 95\% CIs were not directly reported, survival information was extracted from KaplanMeier curves and used to estimate the HR. The log HR and standard error (SE) were used to summarize overall survival outcome [37]. Odds ratios (ORs) and their 95\% CIs were used to assess associations between BANCR expression and tumor parameters, including LNM, DM and tumor stage.

\section{ACKNOWLEDGMENTS}

This article was supported by the National Natural Science Foundation of China (No.81660420), the construction plan of the superior science and technology innovation team of Jiangxi Province (No. 20152BCB24009), and the foreign science and technology cooperation plan of Jiangxi Province (No. 20151BDH80009).

\section{CONFLICTS OF INTEREST}

The authors declare no conflicts of interest.

\section{REFERENCES}

1. Johnsson P, Lipovich L, Grander D, Morris KV. Evolutionary conservation of long non-coding RNAs; sequence, structure, function. Biochim Biophys Acta. 2014; 1840:1063-1071.

2. Guo H, Wu L, Yang Q, Ye M, Zhu X. Functional lincPOU3F3 is overexpressed and contributes to tumorigenesis in glioma. Gene. 2015; 554:114-119.

3. Gu W, Gao T, Sun Y, Zheng X, Wang J, Ma J, Hu X, Li J, $\mathrm{Hu}$ M. LncRNA expression profile reveals the potential role of lncRNAs in gastric carcinogenesis. Cancer Biomark. 2015; 15:249-258.

4. Zhou Y, Wang DL, Pang Q. Long noncoding RNA SPRY4IT1 is a prognostic factor for poor overall survival and has an oncogenic role in glioma. Eur Rev Med Pharmacol Sci. 2016; 20:3035-3039.

5. Cheng N, Li X, Zhao C, Ren S, Chen X, Cai W, Zhao M, Zhang Y, Li J, Wang Q, Zhou C. Microarray expression profile of long non-coding RNAs in EGFR-TKIs resistance of human non-small cell lung cancer. Oncol Rep. 2015; 33:833-839.

6. Zhao QS, Li L, Zhang L, Meng XW, Li LL, Ge XF, Li ZP. Over-expression of lncRNA SBF2-AS1 is associated with advanced tumor progression and poor prognosis in patients with non-small cell lung cancer. Eur Rev Med Pharmacol Sci. 2016; 20:3031-3034.

7. Loewen G, Jayawickramarajah J, Zhuo Y, Shan B. Functions of lncRNA HOTAIR in lung cancer. J Hematol Oncol. 2014; 7:90. 
8. Iguchi T, Uchi R, Nambara S, Saito T, Komatsu H, Hirata H, Ueda M, Sakimura S, Takano Y, Kurashige J, Shinden Y, Eguchi H, Sugimachi K, et al. A long noncoding RNA, lncRNA-ATB, is involved in the progression and prognosis of colorectal cancer. Anticancer Res. 2015; 35:1385-1388.

9. Du Z, Fei T, Verhaak RG, Su Z, Zhang Y, Brown M, Chen Y, Liu XS. Integrative genomic analyses reveal clinically relevant long noncoding RNAs in human cancer. Nat Struct Mol Biol. 2013; 20:908-913.

10. Ferlay J, Soerjomataram I, Dikshit R, Eser S, Mathers C, Rebelo M, Parkin DM, Forman D, Bray F. Cancer incidence and mortality worldwide: sources, methods and major patterns in GLOBOCAN 2012. Int J Cancer. 2015; 136:E359-E386.

11. Siegel RL, Miller KD, Jemal A. Cancer statistics, 2016. CA Cancer J Clin. 2016; 66:7-30.

12. Flockhart RJ, Webster DE, Qu K, Mascarenhas N, Kovalski J, Kretz M, Khavari PA. BRAFV600E remodels the melanocyte transcriptome and induces BANCR to regulate melanoma cell migration. Genome Res. 2012; 22:1006-1014.

13. McCarthy N. Epigenetics. Going places with BANCR. Nat Rev Cancer. 2012; 12:451.

14. Shi Y, Liu Y, Wang J, Jie D, Yun T, Li W, Yan L, Wang K, Feng J. Downregulated Long Noncoding RNA BANCR Promotes the Proliferation of Colorectal Cancer Cells via Downregualtion of p21 Expression. PLoS One. 2015; 10:e122679.

15. Guo Q, Zhao Y, Chen J, Hu J, Wang S, Zhang D, Sun Y. BRAF-activated long non-coding RNA contributes to colorectal cancer migration by inducing epithelialmesenchymal transition. Oncol Lett. 2014; 8:869-875.

16. He A, Liu Y, Chen Z, Li J, Chen M, Liu L, Liao X, Lv Z, Zhan Y, Zhuang C, Lin J, Huang W, Mei H. Overexpression of long noncoding RNA BANCR inhibits malignant phenotypes of human bladder cancer. J Exp Clin Cancer Res. 2016; 35:125.

17. Li L, Zhang L, Zhang Y, Zhou F. Increased expression of LncRNA BANCR is associated with clinical progression and poor prognosis in gastric cancer. Biomed Pharmacother. 2015; 72:109-112.

18. Liao T, Qu N, Shi RL, Guo K, Ma B, Cao YM, Xiang J, Lu ZW, Zhu YX, Li DS, Ji QH. BRAF-activated LncRNA functions as a tumor suppressor in papillary thyroid cancer. Oncotarget. 2016; 8:238-247. doi: 10.18632/oncotarget.10825.

19. Liu Z, Yang T, Xu Z, Cao X. Upregulation of the long noncoding RNA BANCR correlates with tumor progression and poor prognosis in esophageal squamous cell carcinoma. Biomed Pharmacother. 2016; 82:406-412.

20. Peng ZQ, Lu RB, Xiao DM, Xiao ZM. Increased expression of the lncRNA BANCR and its prognostic significance in human osteosarcoma. Genet Mol Res. 2016; 15.

21. Su S, Gao J, Wang T, Wang J, Li H, Wang Z. Long noncoding RNA BANCR regulates growth and metastasis and is associated with poor prognosis in retinoblastoma. Tumour Biol. 2015; 36:7205-7211.

22. Sun M, Liu XH, Wang KM, Nie FQ, Kong R, Yang JS, Xia R, Xu TP, Jin FY, Liu ZJ, Chen JF, Zhang EB, De W, et al. Downregulation of BRAF activated non-coding RNA is associated with poor prognosis for non-small cell lung cancer and promotes metastasis by affecting epithelialmesenchymal transition. Mol Cancer. 2014; 13:68.

23. Zhou T, Gao Y. Increased expression of LncRNA BANCR and its prognostic significance in human hepatocellular carcinoma. World J Surg Oncol. 2016; 14:8.

24. Cho JH, Lee YS, Sun DI, Kim MS, Cho KJ, Nam IC, Kim CS, Kim SY, Park YH, Joo YH. Prognostic impact of lymph node micrometastasis in oral and oropharyngeal squamous cell carcinomas. Head Neck. 2016; 38: E1777-E1782.

25. Li P, Wu F, Zhao H, Dou L, Wang Y, Guo C, Wang G, Zhao D. Analysis of the factors affecting lymph node metastasis and the prognosis of rectal neuroendocrine tumors. Int J Clin Exp Pathol. 2015; 8:13331-13338.

26. Mirzaei H, Gholamin S, Shahidsales S, Sahebkar A, Jaafari MR, Mirzaei HR, Hassanian SM, Avan A. MicroRNAs as potential diagnostic and prognostic biomarkers in melanoma. Eur J Cancer. 2016; 53:25-32.

27. Fan YH, Ye MH, Wu L, Lv SG, Wu MJ, Xiao B, Liao CC, Ji QK, Chai Y, Zhu XG. Overexpression of miR-98 inhibits cell invasion in glioma cell lines via downregulation of IKKepsilon. Eur Rev Med Pharmacol Sci. 2015; 19:3593-3604.

28. Wang Y, Chen W, Yang C, Wu W, Wu S, Qin X, Li X. Long non-coding RNA UCA1a(CUDR) promotes proliferation and tumorigenesis of bladder cancer. Int J Oncol. 2012; 41:276-284.

29. Wu Y, Liu H, Shi X, Yao Y, Yang W, Song Y. The long non-coding RNA HNF1A-AS1 regulates proliferation and metastasis in lung adenocarcinoma. Oncotarget. 2015; 6:9160-9172. doi: 10.18632/oncotarget.3247.

30. Qi P, Du X. The long non-coding RNAs, a new cancer diagnostic and therapeutic gold mine. Mod Pathol. 2013; 26:155-165.

31. Li R, Zhang L, Jia L, Duan Y, Li Y, Bao L, Sha N. Long noncoding RNA BANCR promotes proliferation in malignant melanoma by regulating MAPK pathway activation. PLoS One. 2014; 9:e100893.

32. Jiang W, Zhang D, Xu B, Wu Z, Liu S, Zhang L, Tian Y, Han X, Tian D. Long non-coding RNA BANCR promotes proliferation and migration of lung carcinoma via MAPK pathways. Biomed Pharmacother. 2015; 69:90-95.

33. Wang Y, Guo Q, Zhao Y, Chen J, Wang S, Hu J, Sun Y. BRAF-activated long non-coding RNA contributes to cell proliferation and activates autophagy in papillary thyroid carcinoma. Oncol Lett. 2014; 8:1947-1952.

34. McShane LM, Altman DG, Sauerbrei W, Taube SE, Gion M, Clark GM. Reporting recommendations for tumor 
marker prognostic studies (REMARK). J Natl Cancer Inst. 2005; 97:1180-1184.

35. Altman DG, McShane LM, Sauerbrei W, Taube SE. Reporting Recommendations for Tumor Marker Prognostic Studies (REMARK): explanation and elaboration. PLoS Med. 2012; 9:e1001216.
36. Higgins JP, Thompson SG. Quantifying heterogeneity in a meta-analysis. Stat Med. 2002; 21:1539-1558.

37. Tierney JF, Stewart LA, Ghersi D, Burdett S, Sydes MR. Practical methods for incorporating summary time-to-event data into meta-analysis. Trials. 2007; 8:16. 